
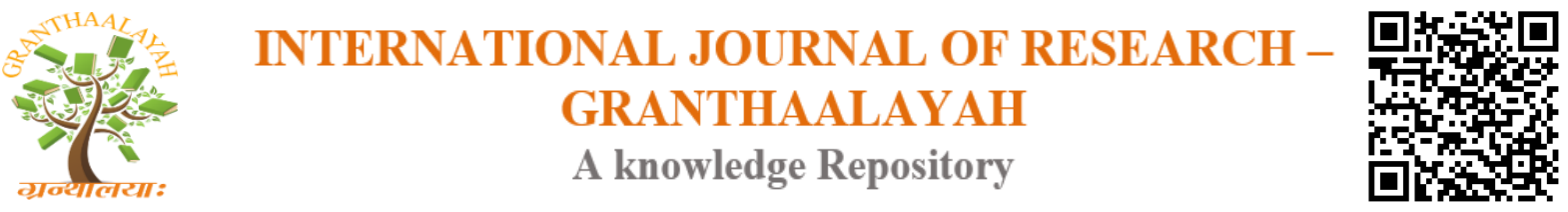

Science

\title{
FREQUENCY AND ANTIMICROBIAL RESISTANCE PATTERNS OF BACTERIA ISOLATED FROM ASPIRATION SPECIMENS OF PATIENTS WITH HIP AND KNEE INFECTIONS AT A HOSPITAL IN BAGHDAD
}

\author{
Hadi Abdulah Abd Ali Al-Zuhairi ${ }^{1}$, Nadheema Hammood Hussein ${ }^{2}$, Khetam Habeeb \\ Rasool $^{2}$ \\ ${ }^{1}$ Abn- Sina Hospital, Ministry of Health, Iraq \\ ${ }^{2}$ Department of Biology, College of Science, Al-Mustansiryah University, Iraq
}

\begin{abstract}
The present study was carried out to determine the frequency of bacteria responsible for hip and knee infections at a hospital in Baghdad/Iraq and to get an updated knowledge about their antibiotic resistance pattern during a period of study which extended from 1 October, 2016 till 1 October, 2017. Identification of bacteria at species level was done by using Analytic Profile Index (API) system (Bio-Merieux, France). The antimicrobial susceptibility test was performed according to Kirby-Bauer (disk diffusion) technique. The frequency of positive aspiration of hip and knee joint infections cultures was 25(65.79\%) cases out of 38 hip and knee joint aspiration. Out of 25 positive aspirations of hip and knee joint infections cultures, 3(12\%) cultures gave mix growth of bacteria. Frequency of positive hip and knee joint infections cultures was higher in male than female patients, $19(76 \%)$ vs. 6(24\%) (P-value $\leq 0.05)$.

Out of 28 isolated bacteria, Gram positive was the most frequently isolated bacteria in hip and knee joint infection cultures, 22(78.6\%) vs. 6(21.4\%) (P-value < 0.05). Staphylococcus epidermidis was the most frequently isolated 13(46.5\%) isolates followed by Staphylococcus aureus isolates $7(25 \%)$. On other hand Pseudomonas aeruginosa was the most frequently isolated Gram negative bacteria 3(10.7\%\%) in hip and knee joint infection cultures.

The most effective antibiotic on Gram-positive isolates was Vancomycin which showed 95.5\%. In Gram negative bacteria the most effective antibiotics were Imipenem (100\%) followed by Amikacin which showed sensitivity rate 83.33.
\end{abstract}

Keywords: Osteomyelitis; Hip and Knee Infections; Bacterial Resistance; Antimicrobial Susceptibility Test.

Cite This Article: Hadi Abdulah Abd Ali Al-Zuhairi, Nadheema Hammood Hussein, and Khetam Habeeb Rasool. (2017). "FREQUENCY AND ANTIMICROBIAL RESISTANCE PATTERNS OF BACTERIA ISOLATED FROM ASPIRATION SPECIMENS OF PATIENTS WITH HIP AND KNEE INFECTIONS AT A HOSPITAL IN BAGHDAD." International Journal of Research - Granthaalayah, 5(12), 10-16. 


\section{Introduction}

Osteomyelitis is the progressive infection of bone and bone marrow by micro-organisms, resulting in inflammatory destruction of bone, bone necrosis and new bone formation. Bone infections differ with regard to duration, etiology, pathogenesis, extent of bone involvement and class of host (1).

Osteomyelitis is generally categorized as acute or chronic based on histopathologic findings, rather than duration of the infection. Acute osteomyelitis is associated with inflammatory bone changes caused by pathogenic bacteria, and symptoms typically present within two weeks after infection. Necrotic bone is present in chronic osteomyelitis, and symptoms may not occur until six weeks after the onset of infection (2).

Osteomyelitis infection is based on open wound, haematogenous or direct bacterial inoculation inside bone (3). It may be occurring direct inoculation of causative organism in bone. Normal bone is highly resistant to infection occur in case of injury, trauma, and existence of foreign bodies (4).

Gram-positive (GP) bacteria, especially Staphylococcus, classically cause this disease, but Gramnegative bacteria have grown in importance as causative agents (5\&6). Such importance can be explained by the increasing number of orthopedic surgeries with the use of implants and, especially, the rising number of high-energy traumas associated with open fractures, as a consequence of traffic accidents and war injuries (7\&8). Progressively, methicillin-resistant Staphylococcus aureus is separated from patients with osteomyelitis (4). Other persistent cases may be caused Pseudomonas aeruginosa, Escherichia coli and Staphylococcus epidermidis (9).

Antibiotic resistance is a constantly evolving phenomenon and a threat to infection and disease control; it complicates patient management and treatment strategy and prolongs hospital stays. Nowadays, this international public health problem is recognised as one of the scourges of the 21 st century (10). The treatment of osteomyelitis should be based on culturing and in vitro antimicrobial susceptibility testing (11). This study was aimed to determine the frequency of bacterial isolates from aspiration specimens of osteomyelitis of hip and knee infections and study their antimicrobial resistance patterns in patients with hip and knee joint during revision arthroplasty at a hospital in Baghdad.

\section{Materials and Methods}

\subsection{Collection of Specimens}

A total of 38 aspiration specimens_were collected from hip and knee joint during revision arthroplasty of patients with osteomyelitis infections in Abn- Sina hospital in Baghdad, Iraq.

\subsection{Period of Study}

This study was conducted during the period extended from 1 October, 2016 till 1 October, 2017. 


\subsection{Isolation and Identification of Bacterial Isolates}

All aspiration specimens from hip and knee joint infections were cultured and the bacteria were isolated according to standard microbiology methods (12), then bacteria were identified at species level by using Analytic Profile Index (API) system (Bio-Merieux, France), including: API Staph for the identification of the Stphylococcus spp, API 20 Strep for the identification of the Streptococcus spp, API $20 \mathrm{E}$ which is a standardized identification system for members of Enterobacteriaceae family and API $20 \mathrm{NE}$ which is a standardized system for the identification of bacteria belong to non Enterobacteriaceae family.

\subsection{Antimicrobial Susceptibility Test}

The antimicrobial susceptibility test was performed according to Kirby-Bauer (disk diffusion) technique (13), using Muller-Hinton agar and different single antimicrobial discs supplied commercially (Hi-Media, India) including: Norofloxacin, Doxyccline, Levofloxacin, Amikacin, Tobramycin, Oxacillin, Moxifloxacin, Tetracycline, Ampicillin, Erythromycin, Vancomycin, Aoxicillin/Clavulanic acid, Aztreonam, Clindamycin, Piperacillin/Tazobbactam, Ceftriaxon, Ceftazidime, Cefepime, Ciprofloxacin, Gentamicin, Imipenem, penicillin G and TrimethoprimeSulphamethoxazole.

Inhibition zones developed around the discs were measured by millimeter ( $\mathrm{mm}$ ) using a metric ruler according to Clinical Laboratories Standards Institute (CLSI, 2011). Results were read according to the National Committee for Clinical Laboratory Standards guidelines (NCCLS) (14).

\subsection{Statistical Analysis}

The analysis was done by SPSS (Statistical Package for Social Sciences) version 16. Categorical variables were reported using frequencies and Fisher's test was used to analyze the significance of different observations. For all analysis, statistical significance was considered at highly significant level $P$-value of $<0.01$, significant level $P$-value of $<0.05$ and insignificant level $P$ value $>0.05$.

\section{Results and Discussions}

\subsection{Study Patients}

Aspiration specimens were collected from 38 patients with hip and knee joint infections during revision arthroplasty in Abn- Sina hospital in Baghdad along a period extended from 1 October, 2016 till 1 October, 2017.

\subsection{Aspiration of Hip and Knee Joint Infections Cultures}

The frequency of positive aspiration of hip and knee joint infections cultures that indicates bacterial infections in the studied patients was $25(65.79 \%)$ cases out of 38 aspiration specimens 
from osteomyelitis of hip and knee joint infections. Out of 25 positive aspirations of hip and knee joint infections cultures, 3 (12\%) cultures gave mix growth of bacteria.

The positive osteomyelitis of hip and knee joint infections cultures were from patients within different ages, but according to gender, frequency of positive osteomyelitis of hip and knee joint infections cultures was higher in male than female patients, $19(76 \%)$ vs. $6(24 \%)(P$-value $\leq$ $0.05)$ as shown in figure- 2 .

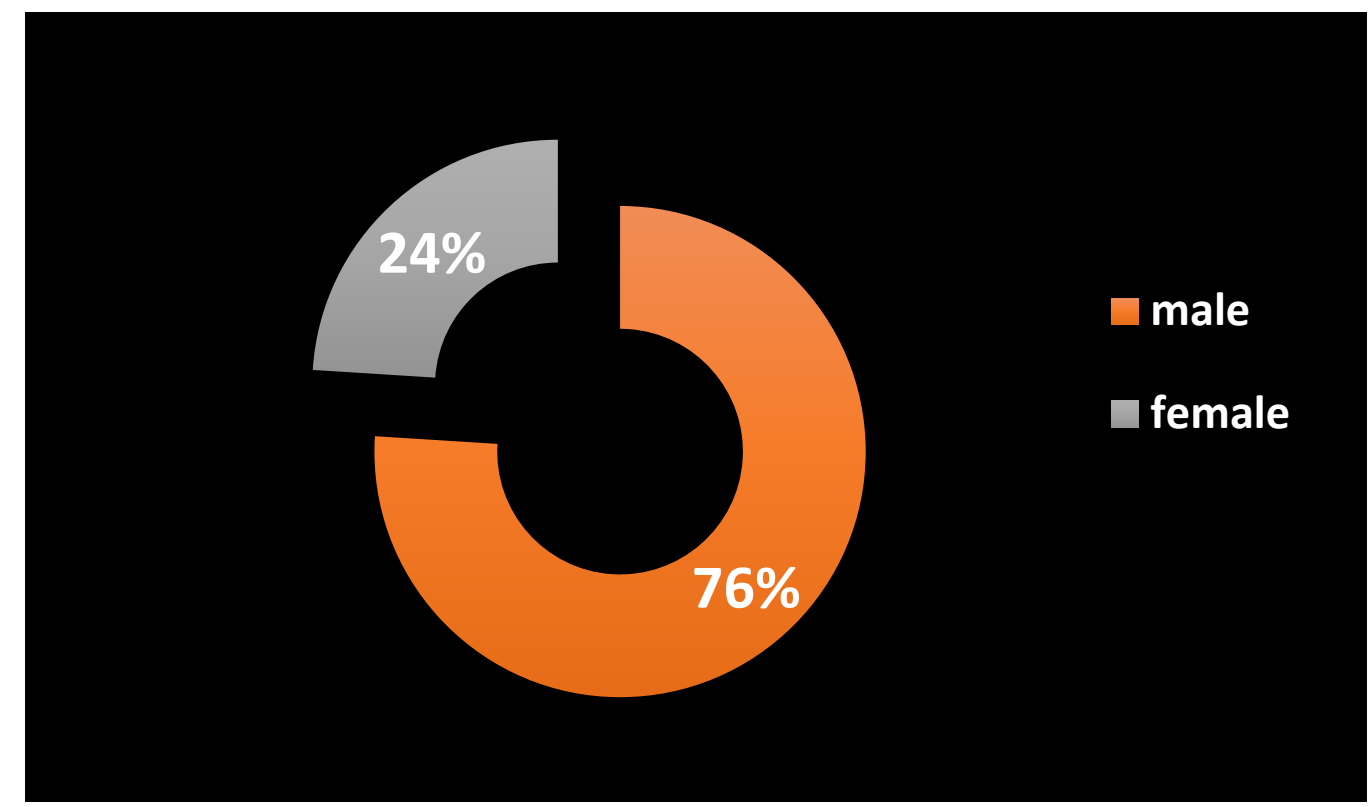

Figure 1: The percentage of male and female with positive hip and knee joint infection cultures

\subsection{Frequency of Bacteria among Aspiration of Hip and Knee Joint Infections Cultures}

Frequencies of isolated bacteria causing osteomyelitis of hip and knee joint infections in AbnSina hospital were summarized in table-1. In which, out of 28 isolated bacteria ( 25 isolates from positive osteomyelitis aspiration of hip and knee joint infections cultures plus 3 isolates from mix growth), the isolation rate of Gram positive and Gram negative isolates was 22(78.6\%) and $6(21.4 \%)$, respectively (figure- 2 ).

From figure-2, Gram positive was the most frequently isolated bacteria in hip and knee joint infection cultures, $22(78.6 \%)$ vs. 6((21.4\%) $(P$-value $<0.05)$.

Table 1: Frequency and distribution of bacterial isolates from blood cultures

\begin{tabular}{|l|l|l|}
\hline Bacterial isolates & No. & $\%$ \\
\hline Staphylococcus epidermidis & 13 & $46.5 \%$ \\
\hline Staphyllococcus aureus & 7 & $25 \%$ \\
\hline Enterococcus faecalis & 2 & $7.1 \%$ \\
\hline Pseudomonas aeruginosa & 3 & $10.7 \%$ \\
\hline Escherichia coli & 2 & $7.1 \%$ \\
\hline Klebsiella pneumoniae & 1 & $3.6 \%$ \\
\hline Total & 28 & $100 \%$ \\
\hline
\end{tabular}




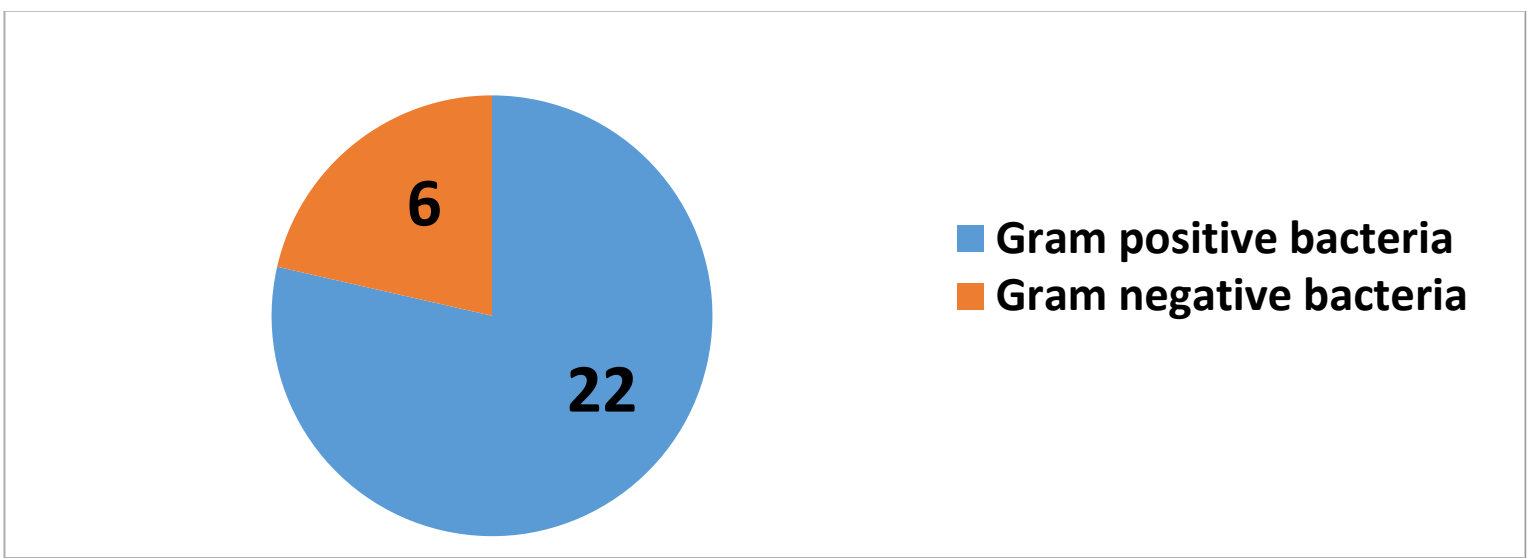

Figure 2: Numbers of Gram -Positive and Gram -Negative bacteria isolated from osteomyelitis of hip and knee joint infection cultures.

As shown in table-1, Staphylococcus epidermidis was the most frequently isolated bacteria in hip and knee joint infection cultures, 13(46.5\%) isolates followed by Staphylococcus aureus isolates $7(25 \%)$.

It also shown in table-1, that Pseudomonas aeruginosa was the most frequently isolated Gram negative bacteria $3(10.7 \% \%)$ in hip and knee joint infection cultures followed by Escherichia coli $2(7.1 \%)$.

The diagnosis of pathogen and effective treatment are necessary to prevent complications of infections (15). Increasing bacterial resistance is linked with the volume of antibiotic prescribed, as well as missing doses when taking antibiotics (16).

In this study, out of 38 aspiration specimens from osteomyelitis of hip and knee joint infections, the frequency of positive cultures_the studied patients was 25 (65.79\%) and Staphylococcus epidermidis was the most frequently isolated bacteria is followed by Staphylococcus aureus. In comparison with other studies, cultures from joint aspiration and tissue specimen identified Staphylococcus aureus and Candida albicans (17). In another study done by (18), showed that Gram-positive organisms caused the majority of hip and knee infections.

\subsection{Antimicrobial Susceptibility Test}

The susceptibility rate to all antibiotics for Gram -Positive and Gram-Negative bacteria was summarized in figure-3 and figure-4, respectively. In Gram-Positive bacteria the most effective antibiotic was Vancomycin which showed $95.5 \%$. This study also showed a highest resistance to penicillin G (95.5\%.) followed by Erythromycin $(86.36 \%)$. On the other hand, the bacterial isolates were revealed different degrees of resistance towards remaining antibiotics figure-3. 


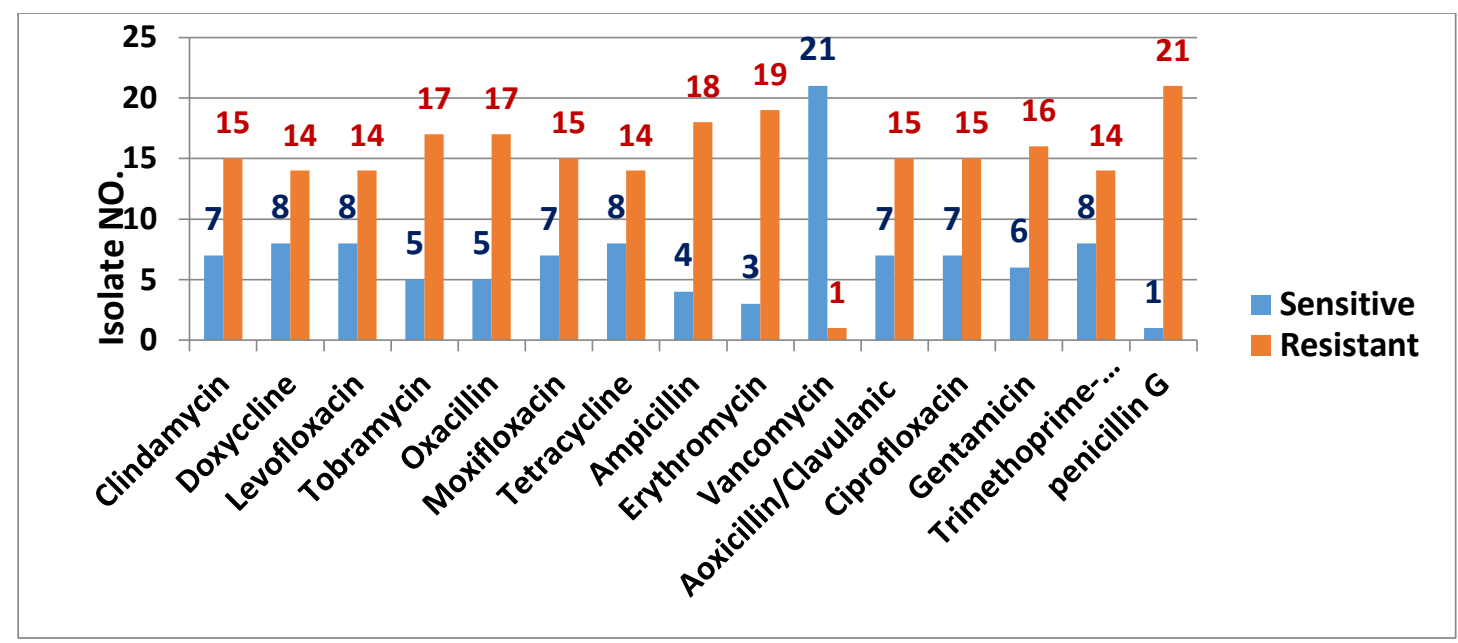

Figure 3: Resistance patterns of Gram-positive isolated bacteria towards various antibiotics

In Gram-Negative bacteria, the most effective antibiotics the isolates were Imipenem (100\%) followed by Amikacin which showed sensitivity rate 83.33. On the other hand, the GramNegative bacteria were revealed different degrees of sensitivity towards remaining antibiotics as shown in figure-4.

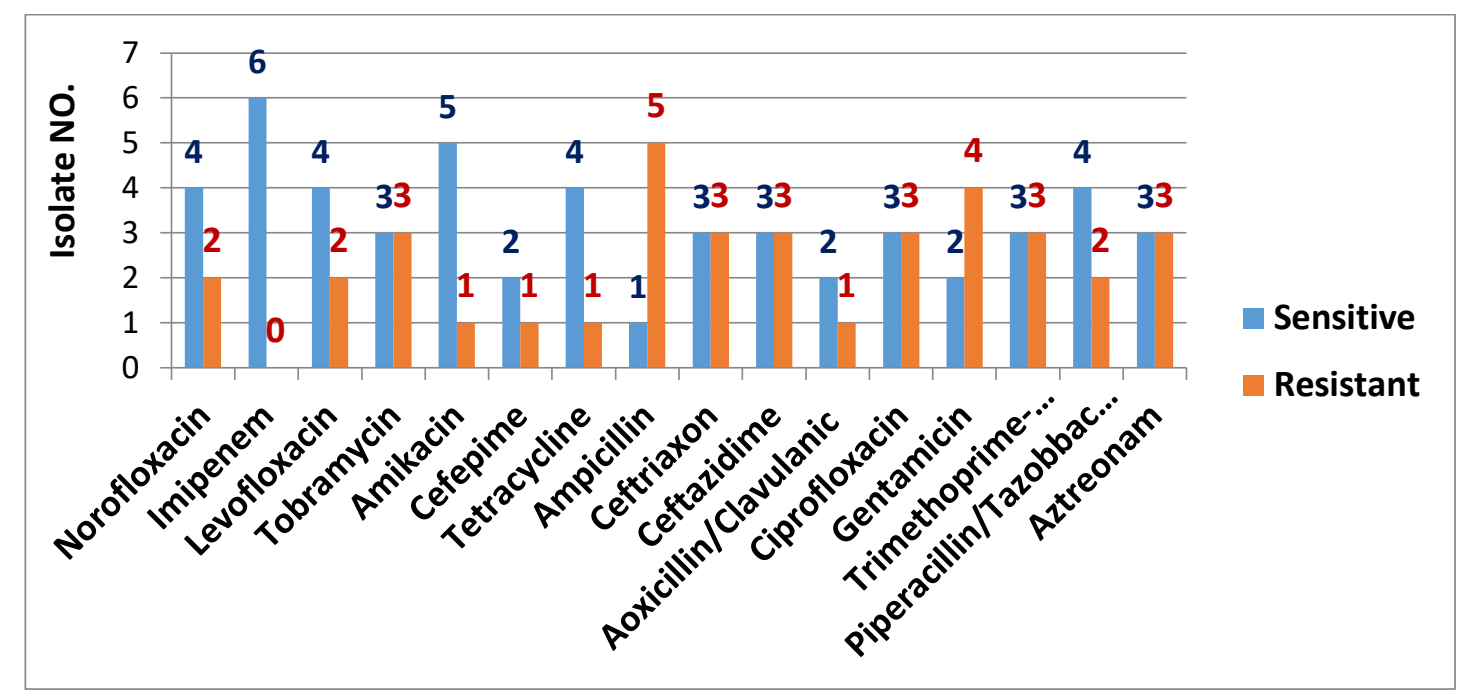

Figure 4: Resistance patterns of Gram-negative isolated bacteria towards various antibiotics

This study showed that Vancomycin was the most effective antibiotic against Gram-Positive bacteria while penicillin $\mathrm{G}$ showed the highest resistance rate, in other hand the most effective antibiotics was Imipenem (100\%) against Gram-Negative bacteria. In comparison with other studies, one study found that $88 \%$ of the bacteria isolated from hip and knee infections were sensitive to gentamicin; $96 \%$, to vancomycin; and $61 \%$, to cefazolin (18).

\section{References}

[1] Lazzarini L, Mader JT, and Calhoun JH.( 2004) .OSTEOMYELITIS IN LONG BONES. J Bone Joint Surg (Am). 86:2305-18. 
[2] Mylona E, Samarkos M, Kakalou E, Fanourgiakis P,and Skoutelis A.(2009). PYOGENIC VERTEBRAL OSTEOMYELITIS: A SYSTEMATIC REVIEW OF CLINICAL CHARACTERISTICS. Semin Arthritis Rheum. 39(1): 10-17.

[3] Waldvogel FA, Medoff G, and Swartz MN .(1970) .OSTEOMYELITIS: A REVIEW OF CLINICAL FEATURES, THERAPEUTIC CONSIDERATIONS AND UNUSUAL ASPECTS. N Engl J Med 282(4): 198-206.

[4] Aragón-Sánchez J, Lázaro-Martínez JL, Quintana-Mar-rero Y, Hernández-Herrero MJ, GarcíaMorales E, et al. (2009). ARE DIABETIC FOOT ULCERS COMPLICATED BY MRSA OSTEOMYELITIS ASSOCIATED WITH WORSE PROGNOSIS? Outcomes of a surgical series. Diabet Med 26(5): 552-555.

[5] Khoo LT, Mikawa K, and Fessler RG. (2009). A SURGICAL REVISITATION OF POTT DISTEMPER OF THE SPINE. Spine J. x.3 (2):130-45.

[6] Berbari EF, Steckelberg JM, and Osmon DR. (2005). OSTEOMYELITIS. IN: MANDELL GL, EDITOR. PRINCIPLES AND PRACTICE OF INFECTIOUS DISEASES. Philadelphia: Elsevier. p. 1322.

[7] Peleg AY and Hooper DC. (2010).HOSPITAL-ACQUIRED INFECTIONS DUE TO GRAMNEGATIVE BACTERIA. N Engl J Med.362 (19):1804-13.

[8] Del Pozo JL and Patel R. (2009). INFECTION ASSOCIATED WITH PROSTHETIC JOINTS. N Engl J Med.361 (8):787-94.

[9] Kohli RandHadley S. (2005) .FUNGAL ARTHRITIS AND OSTEOMYELITIS. Infect Dis Clin North Am 19(4): 831-851.

[10] WORLD HEALTH ORGANIZATION (WHO). (2015). Global actionplan on antimicrobial resistance.

[11] Schulz, K. (2007). OSTEOMYELITIS. IN: Fossum TW, editor. SMALL ANIMAL SURGERY. St. Louis: Mosby; p.1353-1356.

[12] Murray, P. R.; Baron, E. J. and Jorgensen, J. H. (2003). editors: MANUAL OF CLINICAL MICROBIOLOGY, ed 8, Washington DC, ASM Press.

[13] WHO, (World Health Organization). (2003). BASIC LABORATORY PROCEDURES IN CLINICAL BACTERIOLOGY. 2nd ed. Geneva, Switzerland.

[14] Franklin R.; Matthew A.; Karen B.; Michael N. George M.; Dwight J. et al., (2011). PERFORMANCE STANDARDS FOR ANTIMICROBIAL SUSCEPTIBILITY TESTING; TWENTY-FIRST INFORMATION SUPPLEMENT. Clinical and laboratory standards institute (CLSI) (sl). Vol. 31 (1).

[15] Latif, S.; Anwar, M. S. and Ahmad, I. (2009). BACTERIAL PATHOGENS RESPONSIBLE FOR BLOOD STREAM INFECTION (BSI) AND PATTERN OF DRUG RESISTANCE IN A TERTIARY CARE HOSPITAL OF LAHORE. Biomedica. 25: 101 - 105.

[16] Pechère, J. C. (S2001). PATIENTS' INTERVIEWS AND MISUSE OF ANTIBIOTICS. Clin. Infect. Dis. 33(3): 170-173.

[17] Klaus Lerch; Kalteis Thomas; Schubert, T.; Lehn, N. and Grifka, J. (2003). PROSTHETIC JOINT INFECTIONS WITH OSTEOMYELITIS DUE TO CANDIDA ALBICANS. Mycoses. 46 (11-12): 462-466.

[18] Eric Fulkerson; Craig J. Della Valle; Brent Wise; Michael Walsh; Charles Preston; and Paul E. Di Cesare. (2006). ANTIBIOTIC SUSCEPTIBILITY OF BACTERIA INFECTING TOTAL JOINT ARTHROPLASTY SITES. J Bone Joint Surg Am. 88(6):1231-1237.

*Corresponding author.

E-mail address: hadi.alzuhairi2017@gmail.com 